\title{
Business Intelligence as a Source of Competitive Advantage in SMEs: A Systematic Review
}

\author{
Vincent English \\ Department of Informatics, Institute of Technology Blanchardstown \\ Dublin, Ireland \\ Dr. Markus Hoffmann \\ Department of Informatics, Institute of Technology Blanchardstown \\ Dublin, Ireland
}

(C) Author(s). This work is licensed under the Creative Commons Attribution-NonCommercialShareAlike 4.0 International License. To view a copy of this license, visit https://creativecommons.org/licenses/by-nc-sa/4.0/ .

\begin{abstract}
Competitive advantage is the 'Holy Grail' in strategic management theory. What makes a company more successful than its rivals has dominated scholarship in this area for more than 20 years. There have been two main theories proposed to attempt to identify the important resources and capabilities that configure to build competitive advantage; the Resource-based View and Dynamic Capability View. There is a growing literature stream in the area of Business Intelligence $(\mathrm{BI})$ and Big Data Analytics with regard to both the computer technology and business management constructs. However, the literature is silent of the affordances of $\mathrm{BI}$ for Small to Medium Enterprises (SMEs), and so a significant gap in the literature remains. This discussion aims to signal the need to fill that gap and to build awareness of $\mathrm{Bl}$ as a potentially significant contributor to sustained competitive advantage in SMEs underpinned by the iniquitousness of cloud applications previously the domain of Multinational Corporations.

Keywords: Business Intelligence; Competitive Advantage; SME; Capabilities; Key Performance.
\end{abstract}

\subsection{Introduction}

Due to increasing globalisation and rapid changes in technology, SMEs face more significant challenges operating in turbulent markets than their larger competitors. Scholarship in strategic management theory has identified knowledge building capabilities as a critical source of competitive advantage in SMEs (Teece, 2000; Teece and Linden, 2017). The primary objective of this paper is to explore the literature around the main components of $\mathrm{BI}$, examine the extent of its use in SMEs, and determine if it can lead to competitive advantage.

$\mathrm{BI}$ has morphed into a generic term to describe the technologies that support the processes for storing, collecting and analysing data (Wixom and Watson, 2012). Thus, 
$\mathrm{BI}$ is now developing into a separate stream within the strategic management literature related in SMEs to competitive advantage. Competitive advantage may be defined as that thing or things about our business which makes certain customers buy from us, rather than our competitors. The popularity of big data business analytics is increasing exponentially, and the challenge remains as to how SMEs can leverage it and create value in their businesses (Vidgen, Shaw and Grant, 2017). While the increasing importance of $\mathrm{BI}$ is recognised in the literature, the empirical research of its significance from an organisational perspective remains under-researched. Accordingly, this paper presents a systematic review of the extant literature in $\mathrm{Bl}$ and its utility in supporting competitive advantage in SMEs. This emerging practice is known as Business Intelligence (BI) but also referred to as Big Data or Business Analytics (Bayrak, 2015). Thus, the purpose of $\mathrm{Bl}$ is to support better decision making in SMEs.

This paper will start with a quick overview in Section 2.0 of the systematic methodology used to define the boundaries of $\mathrm{BI}$ and SMEs and to discover if there is a new literature stream emerging at the nexus of SMEs, $\mathrm{BI}$ and competitive advantage.

Next, in Section 3.0, the review will define what BI means regarding the SME. The challenges facing the SME is also discussed to the future importance of $\mathrm{BI}$ to competitive advantage in the market. In the section 3.5, the discussion is brought together from the SME perspective with an overview of the interplay between big data and the concept of Bl. The varying technologies are discussed and an attempt at a definition of $\mathrm{Bl}$ is proposed to guide the remaining discussion.

Section 4.0 builds on the definition of BI, but looking at the architecture of technologies that have relevance to the SME. Applications available through cloud servers are specifically targeted, alluding to the hitherto accessibility of powerful data applications which were previously reserved for the large-scale organisations. The section continues with a discussion of $\mathrm{BI}$ situating it firmly in the SME context and building towards the argument that BI can underpin competitive advantage. The final Subsection (4.3) highlights the challenges that SMEs face and suggests that having access to Everything-as-service is not necessarily the sole contributor to competitive advantage.

Section 5.0 suggests a new research stream at the nexus of SMT and BI in SMEs. Both disparate streams of the literature are brought together to lay the foundations for a conclusion on whether using $\mathrm{BI}$ in SMEs can, and will, lead to competitive advantage over its rivals.

\subsection{Review Methodology}

The systematic literature review followed an established protocol recommended by Kitchenham (2004). The stages of the protocol were in three distinct parts. First, a compilation of search terms. Second, a defined list of criteria for inclusion or exclusion of journals and publications. Third, a critical analysis, data extraction and synthesis of 
resulting publications. Normal, Boolean, Proximity and Truncation techniques were used as shown in Table 1.

Table 1: Keywords and descriptors for searching

\begin{tabular}{|c|c|c|c|}
\hline Normal & Boolean & Proximity & Truncation \\
\hline $\begin{array}{l}\text { "Business } \\
\text { intelligence." }\end{array}$ & $\begin{array}{l}\text { Business } \\
\text { Intelligence }\end{array}$ & $\begin{array}{ll}\text { Business } & \text { ADJ } \\
\text { Intelligence }\end{array}$ & Business Intell* \\
\hline "Bl" "SME" & BI AND SME & BI ADJ SME & $\mathrm{Bl}^{*}$ \\
\hline $\begin{array}{l}\text { "Business } \\
\text { intelligence and } \\
\text { competitive } \\
\text { advantage" }\end{array}$ & $\begin{array}{l}\text { "Business } \\
\text { intelligence" AND } \\
\text { "competitive } \\
\text { advantage" }\end{array}$ & $\begin{array}{l}\text { "Business } \\
\text { intelligence" ADJ } \\
\text { "competitive } \\
\text { advantage" }\end{array}$ & $\begin{array}{l}\text { Business } \\
\text { intelligence } \\
\text { competitive* }\end{array}$ \\
\hline $\begin{array}{l}\text { "Business } \\
\text { Analytics" }\end{array}$ & $\begin{array}{l}\text { Business } \\
\text { Analytics }\end{array}$ & $\begin{array}{ll}\text { Business } & \text { ADJ } \\
\text { Analytics } & \end{array}$ & $\begin{array}{l}\text { Business } \\
\text { Analytics* }\end{array}$ \\
\hline "BA" "SME" & "BA AND SME" & BA ADJ SME & BA SME* $^{*}$ \\
\hline $\begin{array}{l}\text { "Business Analytics } \\
\text { and competitive } \\
\text { advantage." }\end{array}$ & $\begin{array}{l}\text { "Business } \\
\text { Analytics" AND } \\
\text { "competitive } \\
\text { advantage." }\end{array}$ & $\begin{array}{l}\text { "Business } \\
\text { Analytics" ADJ } \\
\text { "competitive } \\
\text { advantage." }\end{array}$ & $\begin{array}{l}\text { Business } \\
\text { Analytics } \\
\text { competitive* }\end{array}$ \\
\hline "XaaS and SME" & $\begin{array}{ll}\text { "XaaS" } & \text { AND } \\
\text { "SME" } & \end{array}$ & "XaaS" ADJ "SME" & XaaS SME* \\
\hline $\begin{array}{l}\text { "XaaS and SME } \\
\text { and competitive } \\
\text { advantage" }\end{array}$ & $\begin{array}{ll}\text { "XaaS" } & \text { AND } \\
\text { "SME" } & \text { AND } \\
\text { "competitive } & \\
\text { advantage" } & \end{array}$ & $\begin{array}{l}\text { "Xaas" } \\
\text { "competitive } \\
\text { advantage" }\end{array}$ & $\begin{array}{l}\text { "XaasS } \\
\text { Competitive* }\end{array}$ \\
\hline
\end{tabular}

The list of electronic databases used were: Emerald, Science Direct, IEEE Explore, Springer, Taylor and Francis, Google Scholar and ABI/Inform. The first stage of the search started with papers dated between 2000 and $2010(n=78)$. Relevant papers were scanned through title, abstract and keyword sections of the paper. If papers appeared relevant, the conclusion section was quickly scanned, and discarded if not useful. In the second stage, papers between 2011 and 2017 were accumulated and 
aggregated according to usefulness $(n=63)$. Since the construct of $B I$ only stated to gain momentum in 2010 (Mikalef, et al.), a more rigorous selection process was applied to these papers. The criteria applied were: peer-reviewed journals; scientific rigour, the credibility of claims; and, relevance to topic. A final total of 60 papers were retained.

\subsection{Literature Review}

\subsection{Big data overview}

Big data has become a tool of increasing importance in recent years mediated by the astonishing growth and diversity of the nature of data. This range and diversity have also influenced how data is processed and utilised. The diversity of data has resulted into a deluge of specialisms, ranging from retail consumer analytics to scientific and military applications. According to Tan et al. (2013), the real-time transactional databases of Walmart was 2.5 petabytes in 2011 of customer behaviours and preferences, market trends and activity on different devices. By 2016 , the data deluge had risen to 40 petabytes. Other important areas of data collection are military applications, for example the US Airforce possesses over 30 years of video footage from Afghanistan and Iraq while CERN produces 13 petrabytes of data in 2010 alone (Tan et al., 2013). Big data equates to big news for larger companies allowing them to understand why customer buy what they do, and to build string loyalties in the traditional fickle retail markets.

Big data is rapidly becoming an area of interest in business strategy as well as in social sciences and management generally. According to Mikalef et al. (2018), this new focus on data has been inspired by the wide-scale adoption of social media, reward cards and artefacts that relate to the Internet of Things. There are different epistemological views on 'big' from different ontological perspectives. Hence the usefulness of data from the point of a sensor manufacturer is very different from that of a marketing manager in a cosmetics firm.

There is some debate in the literature to an exact definition of big data, with some researchers focussing on the origins of data, such as whether the data originates in social media, mobile phones (Johnson, 2012), GPS (McAfee, Brynjolfsson and Davenport, 2012), news streams, financial (Sun, Chen and $Y u, 2015)$, and sensors for engineering applications (Babar and Arif, 2017). Big data can be compared to its predecessor, data analytics, where the ultimate goal is to make some sense of the data and use it to gain competitive advantage (McAfee et al., 2012).

The scholarship in this area is starting to move away from the specific affordances of data for different applications, but instead to taxonomy that involves categorisation into domains regarding five 'Vs': value, velocity, veracity, variety, and volume (Akter et al., 2016). This taxonomy describes the economic viability of the data and if the investment costs in harvesting the data bring real value to the SME. In other words, does it make sense for the SME to develop the necessary dynamic capabilities from limited resources? The "Veracity" of the data, which categorises data used is from a trusted 
source; it is authentic and protected, should also be an additional "V" (Demchenko et al., 2013). Seddon and Currie (2017) take it one step further by adding visualisation of the data, where patterns and trends can interpret with some degree of ease in their study of online financial trading.

Nevertheless, the evolving definitions are an indication of the rate at which data is increasing and morphing into different forms for harvesting (Mikalef et al., 2018). Thus, the increasing variability and accessibility of data available are generating dynamic opportunity for SMEs to punch above their weight using evaluation tools previously the exclusive domain of the larger corporations in the past. However, SMEs have proved themselves to slower adopters to the utilisation of big data, and are in danger of being left floundering in the jet stream of their larger rivals. This is a major concern, as larger organisations build capabilities in big data that allow them to detect market trends in advance of SMEs thereby increasing further their dominance. Since SMEs are a vital part of the global economy governments as well as consumers, have cause for concern.

\subsection{Data in the SME context}

The volume rate of generation of data worldwide per day is said to be doubling every 40 months. In 2016, the volume of data created worldwide each day was $2.5 \times 106$ terabytes (Coleman et al., 2016). As discussed in the previous section, the variety, velocity and volume of data is overwhelming and complex. The complexity of data is largely due to the generation of data in different formats: textual, image, sensor, structured, and unstructured data. Traditionally, organisations obtained data through simple databases of customer records, through recording and monitoring. SMEs level of adoption in collecting data from customers varies considerably, as it does in larger organisations. KPMG noted the diversity in their 2015 report adoption of data analytics across different industries and noted that the insurance companies were leaders in the deployment of advanced data analytics (Coleman et al., 2016). The insurance industry was closely followed by banks and supermarkets, and in more recent times, government revenue bodies and healthcare companies. Another concern for the SME is the rapid pace of high levels of refinement in data analytics tailored specifically to meet the needs of specific market. The increasing gulf will lead to sustainable competitive advantage over the long term and force SMEs into more and more specialised niche markets to survive. This trend is highlighted by the report in 2012 found that only $0.2 \%$ of SMEs in the UK were actively adopting data analytics compared with $25 \%$ in larger organisations (e-skills UK, 2013).

A report published by TechNavio, forecast that the compound annual growth rate of SME big data will grow over the period 2014-2018. Therefore because of this rapid growth in the size of big data, those SMEs that still employ traditional methods will find it difficult to manage and analyse it. There is little by way of empirical research into the issues and problems facing SMEs in the adoption of big data analytics. The following section takes a look at the problems and challenges in business analytics for SMEs derived from the literature review. 


\subsection{Challenges in big data analytics for SMEs}

The literature suggests various factors that may explain the lack of adoption by SMEs, some pervasive and some not. The lack of understanding about big data analytics is frequently cited as one of the most serious impediments (e-skills UK, 2013). This can be explained by the tendency of SMEs to operate in niche markets leading to a reduced awareness of business trends outside of their domain specialisms (Coleman et al., 2016). It has also often been commented, that SMEs do not have much interest in markets outside their specialisms and therefore often do not see overarching industry trends that could be profound implications for their niche markets in the future. Another barrier has been identified as an intrinsic conservatism where SMEs are reluctant to change their methods of operation and often have little interest, or indeed confidence, in management trends. A McKinsey report in 2011 highlights the skills shortage in data analytics skills in the market for both large and small organisations a 1.5 million shortfall in the USA alone (Manyika et al., 2011). A similar study by e-skills in the UK highlights that $57 \%$ of recruitment companies experienced difficulties in hiring staff with data analytical skills (e-skills UK, 2013). With the projected growth of $243 \%$ over the period of 2013 (the year of the e-skills report) and 2018 expected, SMEs will simply be priced out of the market for qualified people. Ahlemeyer and Stubbe et al. (2014) are critical of the empirical literature because of the lack of academic case studies successful propagation of innovation in business mediated through big data analytical practices. Thus, stimulating and trend-setting big data SME success stories are not available to enthuse and inspire nascent SMEs.

The lack of transparency in the software market is also an issue for SMEs. Confronted with a dearth of SaaS business applications, for SMEs with little or no experience, it is difficult to select a product that is the most suitable. The front end interface is often too simplistic, or impossibly complex for the non-programmer. Except Watson Analytics from IBM, where pricing plans range from $\$ 20$ to $\$ 40$ per month, there are very few usable off the shelf solutions for the SME and does not involve a steep learning curve. With the advent of GDPR, data security is now an added hindrance for the SME. Although more of an issue for large organisations, SMEs nevertheless rely on older servers to run their businesses. A potential security issue for the SME is the outdated database management systems, for example in 2013 Microsoft ended all support for its 2003 Windows Server. Therefore, legitimate concerns by SMEs are their vulnerability to cyber-attacks and the theft of customer credit card details.

There is a strong correlation between a company who capture and used data effectively and competitive advantage, according to a study published in the MIT Sloan Management Review (Kiron, Prentice and Ferguson, 2012). The main findings were that $67 \%$ of sample companies were convinced that the deployment of data analytical practices leads to at least 'moderate' competitive advantage. More than $50 \%$ stated that data analytics influenced a higher level of innovation, while at the same time, 
shifting the power balance within the organisation. While the larger organisation may have the resources to embrace data analytics into an overall business intelligence system and strategy, where does that leave the SME? What resources are available for the SME to start on that first rung of the ladder, and how can they access the necessary resources? The discussion, therefore, continues with a look at BI systems and how SMEs can utilise them.

\subsection{What is Business Intelligence (BI)?}

$\mathrm{BI}$ has evolved into a general term (first elucidated by the Garner Group in the mid1990s) that encompasses methodologies, databases, machine architectures, analytical algorithms and methodologies (Sharda et al., 2014). Thus, the primary objective of $\mathrm{BI}$ is to facilitate organisations to analyse data in real time to support pragmatic strategic decision making. Accordingly, with interactive access to data in real time, strategists arrive at an informed strategic decision based on the information they have - both current and historical (Turban et al., 2008). This data can be for a wide variety of decisions, for example, marketing, sales promotions, future building requirements, and so on. $\mathrm{Bl}$ is a process using a wide range of tools and applications that transform data into usable information that can then be converted into actions to facilitate actionable informed decisions by key managers. This emerging practice is also known as Big Data or Business Analytics (Bayrak, 2015). No precise definition exists for $\mathrm{BI}$ in SMEs, but for the literature review, will be defined as a wide choice of routines, technologies and algorithms that store, mine, and analyse data which can be used to assist pragmatic business decision making in SMEs.

As is typical in academic scholarship, the definition of construct become confused as the field develops and expands. Bayrak (2015) points out that $\mathrm{BI}$ is preferred by the Information and Communications Technology (ICT) computing community, while the term Business Analytics (BA) is the choice of the business community. Since this review is from the ICT perspective, $\mathrm{BI}$ will be used throughout. BI defines technologies and software platforms that support activities such as metadata management, reporting functions, search tools, Online Analytical Processing (OLAP), data mining modelling and predicting/forecasting data, performance management, Customer Relationship Management (CRM), Management Information Systems (MIS), and, Extraction, Transformation and Loading (ETL) of data. Thus, the techniques available to the SME cover three broad areas: analytics, BI and decision support systems (DSS). They must all interplay together to form one coherent capability in the organisation to harvest and then make use of the data that leads to customer value at the very least. While a detailed discussion of each of these resources is outside the scope of this paper, the following section brings together the idea of big data and business intelligence through the agency of data analytics.

\subsection{The interplay between big data, data analytics, and business intelligence}

In another joint research project between MIT Sloan Management Review and IBM's Institute for Business Value of 4,500 executives, it was found that $58 \%$ responded that 
their competitive advantage increased over the previous year by developing capabilities in big data analytics (Kiron and Shockley, 2011), as described above, the findings are consistent with a later study by Kiron, Prentice and Ferguson (2012). The authors do not give a profile of the respondent companies, so it cannot be assumed that the companies in question were SMEs, or that their findings can be applied to SMEs. However, the authors did find that firms are more likely to benefit from data analytics if they have developed dynamic capabilities in having the right tools, technology and people.

There is no doubt that big data will become an increasingly important part of the business intelligence $(\mathrm{BI})$ strategies of most successful companies in the future. Consider that, by 2020, it is predicted that somewhere in the region of 1.7 megabytes of new data will be created by each human every second, data trails will become the digital equivalent of a user's DNA strand (Marr, 2016). As discussed above, accessing data is one thing, but extracting meaningful information is quite another.

Big data is becoming more accessible to SMEs with lower budgets and limited IT capabilities. SaaS (software-as-a-service) makes storage and analysis technology is now available to rent at an affordable cost. Tools such as Hadoop provide storage and management of big data across networked databases and servers (Marr, 2016). Combine this with amazing technological advancement in ways that data can be analysed through images for facial recognition, text for meaning and sentiment, and predictive analytics. When adding machine learning and artificial intelligence, the requirement to have some engagement in $\mathrm{BI}$ will become a prerequisite even for a threshold capability to compete in the market, let alone competitive advantage.

Next, the paper discussed how the organisation might operationalise access of big data through the development of core-competencies expressed through the configuration of dynamic capabilities.

\subsection{Developing big data dynamic capabilities}

However, this conclusion might seem obvious but building the right kind of dynamic capabilities gets to the heart of the issue. The key is in the "dynamic" insofar that the exogenous high-velocity market conditions are correctly matched by the resources of the firm. This essentially means, that in a market where data is freely available, companies make the best possible use of the data and develop their dynamic capabilities to build a path to value for the firm. Put simply, SMEs must continually redeploy and refresh not only their dynamic capabilities in concert with their analytical insights but also the organisational resources necessary to turn this new knowledge into effective and profitable actions. With the rapidity of change in technology and the inevitable proliferation of more and more data, the SME who does not embrace this new market "force" is in danger of being out-competed by its rivals. There is a case for 
revisiting the staid 5-Forces Model proposed by Porter (1985), and propose a new, 6 Forces Model to include technology and big data.

The construct of dynamic capabilities is relatively new, and there is still no coherent definition. Since its evolution from the Resource-based View (RBV), two main streams have evolved. The first is dynamic capabilities that are essentially well-developed routines (Eisenhardt, Furr and Bingham, 2010; Eisenhardt and Martin, 2000). As such, they can be copied and are therefore not a source of competitive advantage. The alternate view that dynamic capabilities are not simply routines, or routines build on routines, but capabilities that are developed from the ground up in response to the challenges of the market (Pierce, Boerner and Teece, 2002; Teece, 2018; Teece and Pisano, 1994). Hence, in Teece's version, dynamic capabilities cannot be bought, they must be firm specifically developed.

The literature streams have at least developed to take account of the various forms of capabilities that exist in firms. However, it should be noted that the literature is very weak in its treatment of SMEs and thus represents a significant gap in the research. The body of scholarship does now recognise that capabilities operate quite differently from one another, both within the firm and between firms. Hence, capabilities can result in vast differences in firm performance and competitive advantage (Hoopes and Postrel, 1999). In addition, the firm must be agile enough, financially stable and adaptive to deliver value to the market, while at the same time, reap the financial benefits. The resources available to the SME can often be limited, so an effective, efficient and swift method of gathering valuable market knowledge will be of significant advantage over rivals.

\subsection{Building dynamic capabilities through big data analytics}

As described above, Akter et al. (2016) showed that through the leveraging of big data analytics, noticeable gains in performance could be achieved. However, little attention was given in the study to defining the specific resources required to develop the capabilities to leverage such gains. Indeed, the literature is silent on how microfoundations build in SMEs and they are orchestrated in such a way as to develop strong big data analytical capabilities. Thus, there is a significant gap in the literature where empirical research into mechanisms whereby SMEs can leverage "Everything as a Service" (XaaS) bespoke packages in a cost-effective way as a factor in developing a competitive advantage.

Gupta and George (2016), building on the resource-based theory, propose that the answer is looking at the resources in the firm. Resource-based theory (RBT) was developed by Barney (2007) and later developed by others (For example, Helfat and Peteraf, 2003; Kraaijenbrink, Spender, and Groen, 2010; Mahoney and Pandian, 1992; Priem and Butler, 2001; Roy and Khokhle, 2011; Wernerfelt, 1984; Winter, 2000). RBT is based on the premise that competitive advantage is gained by 
developing unique resources within the firm that are heterogeneous with respect to their competitors (Grant, 2005) and that are unique and difficult to imitate (Barney, 1991). Therefore, the RBT view takes a different perspective to that of the more standard approach of Porter (1985) that views competitive advantage in terms of external market forces. Instead, RBT looks inward towards the tangible and intangible resources of the firm and human skills and knowledge.

The taxonomical characteristics of big data lie, inter alia, in their volume, variety and velocity (Mikalef et al., 2018). However, what is frequently overlooked, is the quality and fitness for the purpose of the data. While data is rapidly becoming a critical resource within the firm, a McKinsey report in 2011 identified data as an equally crucial factor in the firm as the traditional tangible assets such as capital, labour and commercial assets (Manyika et al., 2011). Therefore, ownership of valuable data can be considered to be a critical tangible asset along with firm infrastructure, property, cash and IT systems.

The acquisition of data and its effective use is governed by the intangible assets of the firm. This involves in keeping up with knowledge and skills, which is not always possible for an SME. Tallon et al. (2013) recognise the importance of managing growing volumes of data in the organisation and propose a framework detailing the structures and processes that need to be in place to manage data. While, there are echoes of dynamic capabilities, but from a different perspective, yet again, there is a failure to recognise the fundamental challenges that face the SME. In order for data to be used effectively by the SME (where resources are in short supply), the data must be packaged and operationalised with as little effort and cost as possible. Elaborate frameworks with presupposed resources in place, simply do not wash with the reality of operating as an SME. LaValle et al. (2011) correctly recognise that a data-driven culture is an important factor in the continued success of the firm. This brings the focus back on the dynamic capabilities in the firm, where the culture for using big data will be embraced by top management right down to the individual worker (Gupta and George, 2016).

The third pillar of RBT is the human skills, knowledge and competencies. It is tempting to draw upon elaborate organisational structures whereby the division of responsibilities for the harvesting and deployment of big data delineates through database managers, programmers, cloud services managers, and so on. In reality, that multi-functional approach is not available to SMEs. Lamba and Dubey (2015) point to the importance of a "fact-based" learning culture and the inevitable top management support, which is relevant to any organisation regardless of size.

Despite the hype surrounding big data and the much heralded enormous potential, empirical research into the dynamic capabilities that need to be developed in SMEs remains under researched. Indeed, the authors are not aware of any active research 
in this area. The solution may potentially lie in SMEs forming strategic alliances with other SMEs who specialise is data harvesting. In doing so, the potential for bounded rationality is reduced, relational competencies are increased, and SMEs can grow and develop inter-relational skills. How this might be achieved will be discussed in the following section in the light of what resources are already available in the market.

\subsection{Areas of big data analytics}

The discussion now continues with the major component of the architecture of $\mathrm{BI}$, namely: (i) the data warehouse, (ii) business analytics, and (iii) business performance management (Sharda et al., 2014). In 2006, the umbrella term "Business Intelligence" emerged as more and more commercial products started to appear on the market, with the Garner Group popularising the construct in the mid-1990s (Sharda et al., 2014). Typical BI systems are composed of four inter-relational components: (i) user interface; (ii) business analytic tools; (iii) data warehousing; and, (iv) business performance algorithms. The relational functionality of the four components elucidated in the way in which low granular data is stored, transformed and realigned to provide high-quality information allowing the manager to execute actionable pragmatic decisions.

A Data Warehouse (DW) can be described as a repository of data both current and historical that has, as its primary function, to facilitate actionable decision-making by managers (Turban et al., 2008). So that the data is of maximal utility, it needs to be available in a structured format (Sharda et al., 2014). Data that is not organised and resident in a database is generically labelled as being unstructured. Such unstructured data describes textual (e-mails, Word files, PowerPoints etc), and non-textual (media files such as JPEGs, MP4, MPEGs etc). The data is there for a reason, and that reason is to support the managerial decision-making processes. Accordingly, the data is then suitable for online analytical processing (OLAP), data mining, reporting and other decision-making applications. The DW can be available as a cloud application or resident on the servers in the organisation. DW is, of course, desirable but not always feasible in an SME environment (in particular for the smaller of the SMEs) For senior managers (or business owners) to make informed and accurate decisions, accurate and timely information is needed through a business reporting system. Reports (whether digital or paper) form the basis of communication of raw information required for decision-makers. There is a wide variety of $\mathrm{BI}$ related business reporting, for example (Sharda et al., 2014):

- Matrix Management Reports - Lean Six Sigma (Keller, 2011; Kumar et al., 2008); Total Quality Management (TQM) (Ghobadian and Gallear, 1996); Strategy Mapping and Key Performance Indicators (KPI) (Kaplan and Norton, 2001, 2004).

- Dashboard-Type Reports - A range of performance indicators are presented on one screen or a single page. They are usually bespoke and predefined (for example SAP Business Objects Dashboards). 
- Balanced Scorecard Reports - Developed by Kaplan and Norton (ibid) as a process to give an integrated overview on financial, business, knowledge management and growth metrics in a single report (Kaplan and Norton, 2001, 2004).

Thus, a business reporting system can be considered in a generic sense as a continuum where the data source is at one end and the manager at the other (Turban et al., 2008). Accordingly, the data is structured, sorted and arranged into reports that have been specifically designed for the organisation (usually larger firms), or as a standard cloud-based application (for SMEs). The main components consist of a data supply, where events and transactions are recorded, filtered and sent in batches or in real time to a data storage repository. The data may originate online through web servers, the point of sale systems (POS), enterprise resource planning (ERP), or barcode readers, to name but a few. This process, known as Online Transaction Processing (OLTP) facilitates the delivery of the structured data to the repository or DW. The storage area is then in the form of a relational database where OLAP (for example, Cube functions) are used to stratify and extract the data (BI analytics) for BI intelligence reporting. The way data is recorded, structured, and analysed must suit the need of the business, and thus business logic is an important consideration. The critical step of capturing the data and delivering it in the form of an actionable report is through a well-defined process known as Extract, Transform, and Load (ETL). This critical process is the quality assurance stage where the data is correctly structured around the reports required (Sharda et al., 2014).

\subsection{Accessibility of BI Applications}

The evolution of $\mathrm{BI}$ has not only revolutionised access to powerful applications for the SMEs but has created acronym heaven. Cloud applications and the ubiquity of enterprises offering data management solution have resulted in the SMEs having access to powerful applications and computing hardware previously only available to large organisations. Services range from Software-as-service (SaaS), where payroll, tax or HR service are outsourced, to Everything-as-service (XaaS); almost everything from computing to database management is outsourced to the cloud. While it is outside of the scope of this literature review to delve too deeply into every gradation of outsourcing, Table 2 delineates the various options available. It can be seen that the ubiquity of affordable internet services is now placing the SMEs at an advantage previously only in the domain of the large organisation of multinationals.

Table 1: Outsourcing "as service" functions (Author's own elaboration)

\begin{tabular}{|l|l|l|}
\hline Acronym & Meaning & Advantage to the SME \\
\hline XaaS & $\begin{array}{l}\text { Everything as a } \\
\text { Service }\end{array}$ & $\begin{array}{l}\text { All technology delivered through the internet - } \\
\text { the ultimate IT outsourcing. }\end{array}$ \\
\hline
\end{tabular}




\begin{tabular}{|l|l|l|}
\hline IaaS & $\begin{array}{l}\text { Infrastructure as a } \\
\text { Service }\end{array}$ & $\begin{array}{l}\text { All hardware, software, networking, security, } \\
\text { storage available through a service provider at } \\
\text { a lower cost compared to owning all the system } \\
\text { to the SME while remaining in control of their } \\
\text { data. }\end{array}$ \\
\hline SaaS & Software as a Service & $\begin{array}{l}\text { The software is available to the SME from a } \\
\text { vendor over the internet (typically) allowing } \\
\text { access to applications previously only } \\
\text { accessible to large companies. }\end{array}$ \\
\hline BPaaS & $\begin{array}{l}\text { Business Process as } \\
\text { a Service }\end{array}$ & $\begin{array}{l}\text { Typical outsourced functions such as HR, } \\
\text { payroll, marketing, PR, SEO for example } \\
\text { extremely cost-effective for micro-SMEs. }\end{array}$ \\
\hline UCaaS & $\begin{array}{l}\text { Unified } \\
\text { Communications as a } \\
\text { Service }\end{array}$ & $\begin{array}{l}\text { SME can integrate services such as: VOIP; } \\
\text { audio conferencing; integrated e-mail/SMS/fax; } \\
\text { mobile communications convergence (phone, } \\
\text { interactive whiteboards), through a third-party } \\
\text { provider without having to invest heavily in such } \\
\text { infrastructure. }\end{array}$ \\
\hline DaaS & Desktop as a Service \\
MaaS & $\begin{array}{l}\text { A virtual desktop cloud service offered by a } \\
\text { third-party provider for a monthly fee. Ideal for } \\
\text { the micro-SME who are predominantly mobile. }\end{array}$ \\
\hline & $\begin{array}{l}\text { Outsourced central operation of computer } \\
\text { servers whether on-site or remotely. The } \\
\text { advantage for SMEs is that their back-up is } \\
\text { managed and always have access to the latest } \\
\text { software. }\end{array}$ \\
\hline
\end{tabular}

\subsection{Business Intelligence (BI) in SMEs}

Knowledge building repertoires are one of the critical capabilities needed for the SMEs' drive towards competitive advantage (Grant, 1996). Collection of data (for example, customers, services, products, demographics) is a significant contributor to the development of knowledge in the firm. Larger organisations have recognised the value of this data contained in databases and data warehouses and have leveraged this into actionable processes to better understand their markets, customers or products. Where SMEs operate in turbulent markets, the need to develop knowledge capabilities is more critical (Argote and Ingram, 2000). Managers need to be able to get accurate 
information rapidly so that opportunities are not lost, nor threats from rivals missed. Hence the marketing mantra from the companies supplying $\mathrm{BI}$ solutions (Sharda et al., 2014).

The target market for commercial $\mathrm{BI}$ products remains the domain of the large companies due to their higher complexity, larger customer bases, more complex projects, and their financial resources (Guarda et al., 2013). The ubiquity of data available and how it can generate new sources of value (for example Amazon, Tesco, etc.) is becoming a tool that can analyse patterns of customer behaviour as well as predict future customer preferences (George, Haas and Pentland, 2014), and more cloud-based third part solutions are becoming more readily accessible to SMEs (as discussed above).

The challenge facing the SMEs is not how to efficiently manage their data, but to harvest strategically important new data. BI should be regarded as a defined management approach and not just a technology (Guarda et al., 2013). Thus, BI allows the SME to integrate information (data) for analysis, reporting, accessing key performance indicators (KPls), marketing and so on. Accordingly, having access to historical data and harvesting new industry data, the SMEs can recognise previously unknown patterns and gain a better understanding of business processes and future market trends (Reeves and Deimler, 2009). With the availability of cloud-based solutions, Software-as-a-Service (SaaS) allows the SMEs to access technology that was previously only in the domain of the larger companies. Thus, the SMEs can: improve the quality of their information systems; gain access to modern, powerful computing applications; and, use financial resources in other areas of the company. With its origins in database management, modern $\mathrm{Bl}$ still relies extensively on technologies that collect, extract and analyse data (Turban et al., 2015).

\subsection{Decision-making challenges and $\mathrm{BI}$}

According to Sharda et al. (2014), the computer technologies at the disposal of managers in organisations today can have a significant influence on the formulation of corporate strategy and hence competitiveness and performance. The critical challenge for all organisations, particularly SMEs, is how to leverage the available data and hence create value for the business (Vidgen, Shaw and Grant, 2017). Moreover, the challenges facing business are not just of a technical issue, but also of an organisational, personnel and knowledge management considerations as well. For example, how efficiently will managerial agency implement, or recognise, the data presented to them? How well will the data be aligned to the mission, vision, values and overall strategic direction of the business? Five main challenges are identified in the literature for which organisations should overcome to be a strategically data-driven enterprise (McAfee, Brynjolfsson and Davenport, 2012). These five challenges (shown in Table 3) demonstrate that access to, and familiarity with, data analytics is not merely a matter of possessing dynamic technical capabilities (Ahenkora and Adjei, 2012; Chang, 2012). Borrowing from Vidgen, Shaw and Grant (2017), and merging the four- 
dimensional model of organisation change (Nerur, Mahapatra and Mangalaraj, 2005) the following table elaborates on the five main challenges facing the organisation.

Table 3: Challenges facing integration of $\mathrm{BI}$ in organisations

\begin{tabular}{|c|c|c|c|}
\hline $\begin{array}{l}\text { Organisational } \\
\text { change factors }\end{array}$ & \begin{tabular}{|l|}
$\begin{array}{l}\text { Challenge for } \\
\text { the } \\
\text { organisation }\end{array}$ \\
\end{tabular} & $\begin{array}{l}\text { Supporting } \\
\text { resources in } \\
\text { organisations }\end{array}$ & References \\
\hline \multirow{2}{*}{ People } & Leadership & \begin{tabular}{|lr} 
Leadership and \\
direction from senior \\
management
\end{tabular} & $\begin{array}{l}\text { (Adair, 2010; Augier and } \\
\text { Teece, 2009; Teece, 2012; } \\
\text { Beck and Wiersema, 2013). }\end{array}$ \\
\hline & \begin{tabular}{|l} 
Talent \\
Management
\end{tabular} & \begin{tabular}{|l|} 
Effective \\
management and \\
strategic training
\end{tabular} & $\begin{array}{l}\text { (Adner and Helfat, 2003; } \\
\text { Agarwal et al., 2004; Elberse } \\
\text { and Ferguson, 2013). }\end{array}$ \\
\hline Technology & Technology & \begin{tabular}{|lr} 
Integration & and \\
effective, & strategic \\
choice & of \\
technologies &
\end{tabular} & 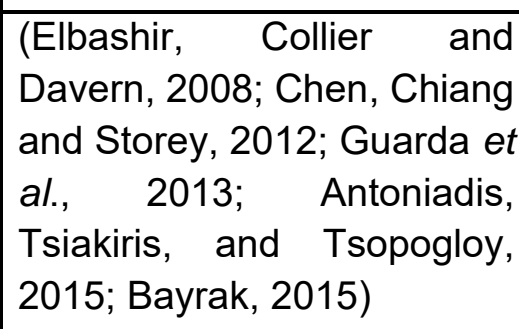 \\
\hline \multirow{2}{*}{ Culture } & Decision-making & $\begin{array}{l}\text { Timely, informed, } \\
\text { agile, decisive and } \\
\text { pragmatic decisions } \\
\text { made for the } \\
\text { business }\end{array}$ & $\begin{array}{l}\text { (Beach and Mitchell, 1996; } \\
\text { Argote and Ingram, 2000; } \\
\text { Adner and Helfat, 2003; } \\
\text { Appelbaum et al. 2017) }\end{array}$ \\
\hline & $\begin{array}{l}\text { Company } \\
\text { culture }\end{array}$ & $\begin{array}{l}\text { Fostering a sense of } \\
\text { innovation and } \\
\text { ethical harvesting of } \\
\text { data usage. }\end{array}$ & $\begin{array}{l}\text { (Dubey et al.; 1982; Becker, } \\
\text { 1982; Treacy and Wiersema, } \\
\text { 1993; Achtenhagen, Melin } \\
\text { and Naldi, 2013). }\end{array}$ \\
\hline
\end{tabular}

\subsection{Competitive advantage for the SME}

Companies that constructively manipulate and harvest data are more productive (5\%) and more profitable (6\%) than those that do not, according to McAfee and Brynjolfsson (2012). The discussion thus far has highlighted the need for quality decision making 
by managers based on quality data. While the literature recognises that the data cannot always be perfect, it must, at least, be fit for purpose (Haug and Arlbjørn, 2011). The literature also stresses the importance of pre-cleaning and pre-processing of the data thus facilitating more time for modelling and value-added analysis (Vidgen, Shaw and Grant, 2017). If third party providers can provide data in a usable form, then the SME is able to strategically align the use of data correctly with all its resources and is in a good position to gain a competitive advantage against its rivals (Vidgen, Shaw and Grant, 2017). Current theories that attempt to explain why a firm may gain a competitive advantage in the marketplace are the Resource-based Theory (RBV), and its derivative, the Dynamic Capability View (DCV). Under RBV in order to attain a competitive advantage, the firm must develop resources that are valuable to customers, rare, inimitable (not easily copied) and non-substitutable by rivals (Barney and Clark, 2007). These so-called VRIN conditions explain the type and functions of resources that attain and maintain competitive advantage (Eisenhardt and Martin, 2000). Thus, the SME that can develop its BI capabilities, leveraged through XaaS providers, is in a position to put the building blocks together towards a competitive advantage over its rivals. While this area remains underdeveloped in the literature, there are some studies that have suggested that high $\mathrm{BI}$ capability strengthens operation capabilities when aligned correctly with Supply Chain Management (SCM) initiatives (Chae et al., 2014). Similarly, Erevelles, Fukawa and Swayne (2016) in their study of how BI transforms marketing in organisations refer to the "big data revolution" in consumer markets. This is where the unprecedented volumes of data are available with incredible variety and hyper-velocity. The firms who rigorously analysed their data more than double that of their competitors enjoyed more significant growth and increased efficiencies. The authors concluded that competitive advantage was predicated on an analytics-driven management culture.

In summary, while the literature is sparse in its treatment of $\mathrm{BI}$ as a microfoundation towards dynamic capabilities in SMEs, the preponderance of scholarship acknowledging the utility of $\mathrm{BI}$ activities creating critical capabilities that are VRIN and hence fundamental to competitive advantage is a rapidly growing construct in both Data Analytics as well as Strategic Management Theory. This review concludes with a synthesis of the evidence surrounding SMEs and the affordances of BI.

\subsection{Conclusion}

This paper contributes to the debate on the affordances of $\mathrm{BI}$ about SMEs. The discussion attempted to bring together tenets of strategic management theory focussing on the resources within the company, and the strategic advantage that a carefully managed $\mathrm{BI}$ approach can bring. The paper has highlighted the challenges facing the SME in gathering important market intelligence quickly and accurately. The discussion also elaborates on the strategic importance attributed to people, technology and culture in the SME sector and suggests that it is a fertile area for future research into the nexus between $\mathrm{BI}$ and agility and how this builds towards dynamic capabilities. 
$\mathrm{BI}$ and the theories of competitive advantage are both in their relative infancies in their respective fields. The evidence from the systematic literature review uncovered deficiencies and lack of empirical studies focussed on SMEs and BI. Thus, it is hard to make a definitive judgement on the affordances of BI for SMEs, because the mere fact of having access to structured data is not a guarantee of success by any means. Instead, the knowledge and expertise available to the SME as human factors are still critical. The issue also remains one of the financial constraints for the SME insofar as not being able to implement decisions based on opportunities presented from the evaluation of big data. In conclusion, the evidence suggests, despite the gap in the literature, SMEs who embrace $\mathrm{BI}$ even to a small extent, stand a better chance of attaining a competitive advantage over their rivals.

The economies of scale provided by third-party cloud computing suppliers also play an important role in assisting the SME to not only outperform their similarly sized rivals but to establish threshold core competencies to compete with much larger rivals. The efficiencies created in SMEs through outsourcing is building a firm base on which to compete effectively.

It would appear that $\mathrm{BI}$ is a paradigm shifter, and is not some fad, but a reality for all businesses, and it is here to stay. Accordingly, there are vast opportunities for further research in the area of $\mathrm{BI}$ in SMEs and how it can connect across different academic domains. For example, further research into decision making by SMEs and how $\mathrm{BI}$ can contribute to dynamic capability building is a potential game-changing area. Additionally, Bl should be considered as an integral part of the forces that act on business from both a SMEs' and multinationals' perspective.

The ever-increasing volume of data available and the exponential increase in companies using big data as the basis of strategic planning is becoming more accepted. However, the empirical analysis given to SMEs regarding how they should gather, then effectively manage the data remain silent on this business paradigm. Dynamic capability theory has been heralded as the next great hope to understand how a firm can attain a competitive advantage, but yet, the theory has failed to recognise a significant capability: knowledge through data acquisition. This paper has aimed to highlight this seemingly obvious resource available to all organisations regardless of size. Data is ever present, whether it is the freely available information on government websites or the simple statistics of who is visiting the website of the SMEs.

The main argument put forth in this paper is that the real value of data to the SME depends on associations, strategic alliances and capabilities developed in the firm to take advantage of the data it gathers. It is not just a simple matter of employing an algorithm to delineate hidden patterns or predictive analytics from a dataset, but the competences of the firm as a whole to correctly interpret what they discover and correctly operationalise their findings in such a way that their customer offering is unique and hard to imitate by their competitors. 


\section{References}

Achtenhagen, L., Melin, L., and Naldi, L. (2013) 'Dynamics of business models - strategizing, critical capabilities and activities for sustained value creation', Long Range Planning, 46(6), pp. 427-442.

Adair, J. (2010) 'Leadership for innovation: How to organize team creativity and harvest ideas', Human Resource Management International Digest, 18(6) pp.185

Adner, R., and Helfat, C. (2003) 'Corporate Effects and Dynamic Managerial Capabilities', Strategic Management Journal, 24(10), pp. 1011-1025.

Agarwal, R., Echambadi, R., Franco, A. M., and Sarkar, M. B. (2004) 'Knowledge transfer through inheritance: spin-out generation, development, and survival', Academy of Management Journal, 47(4), pp. 501-522.

Ahlemeyer-Stubbe, A. (2014) A practical guide to data mining for business and industry. Chichester, West Sussex, United Kingdom: Wiley.

Akter, S., Wamba, S. F., Gunasekaran, A., Dubey, R., \& Childe, S. J. (2016) 'How to improve firm performance using big data analytics capability and business strategy alignment?', International Journal of Production Economics, 182, pp. 113-131.

Ahenkora, K., and Adjei, E. (2012). 'A Dynamic Capabilities Perspective on the Strategic Management of an Industry Organisation', Journal of Management and Strategy, 3(3), pp. 21.

Antoniadis, I., Tsiakiris, T. and Tsopogloy, S. (2015) 'Business Intelligence During Times of Crisis: Adoption and Usage of ERP Systems by SMEs', Procedia - Social and Behavioral Sciences, 175, pp. 299-307.

Appelbaum, D., Kogan, A., Vasarhelyi, M., and Yan, Z. (2017) 'Impact of business analytics and enterprise systems on managerial accounting', International Journal of Accounting Information Systems, 25, pp. 29-44.

Argote, L., and Ingram, P. (2000) 'Knowledge transfer: A basis for competitive advantage in firms', Organizational behavior and human decision processes, 82(1), pp. 150-169.

Augier, M., and Teece, D. (2009) 'Dynamic capabilities and the role of managers in business strategy and economic performance', Organization Science, 20(2), pp. 410-421.

Babar, M., and Arif, F. (2017) 'Smart urban planning using Big Data analytics to contend with the interoperability in Internet of Things', Future Generation Computer Systems, 77, pp. 6576.

Barney, J. (1991). 'Firm resources and sustained competitive advantage', Journal of Management, 17(1), p. 99-120.

Barney, J. B. and Clark, D. N. (2007) Resource-based theory: creating and sustaining competitive advantage. Oxford: Oxford University Press. 
Bayrak, T. (2015) 'A review of business analytics: A business enabler or another passing fad', Procedia - Social and Behavioral Sciences, 195, pp. 230-239.

Beach, L. R., and Mitchell, T. R. (1996) 'Image theory, the unifying perspective', in Beach L. R. (ed.) Decision making in the workplace: $A$ unified perspective. Mahwah, $\mathrm{NJ}$ : Lawrence Erlbaum Associates, pp. 1-20.

Beck, J. B., and Wiersema, M. F. (2013) 'Executive decision making: Linking dynamic managerial capabilities to the resource portfolio and strategic outcomes', Journal of Leadership \& Organizational Studies, 20(4), pp. 408-419.

Becker, H. S. (1982) 'Culture: A sociological view’, Yale Review, 71(4), 513-527.

Chae, B. K., Yang, C., Olson, D., and Sheu, C. (2014) 'The impact of advanced analytics and data accuracy on operational performance: A contingent resource based theory (RBT) perspective', Decision support systems, 59, pp.119-126.

Chang, C. C. (2012) 'Exploring IT entrepreneurs' dynamic capabilities using Q-technique', Industrial Management \& Data Systems, 112(8), pp. 1201-1216.

Chen, H., Chiang, R. H., and Storey, V. C. (2012) 'Business intelligence and analytics: From big data to big impact', MIS Quarterly, 36(4), pp. 1165-1188.

Coleman, S., Göb, R., Manco, G., Pievatolo, A., Tort-Martorell, X., and Reis, M. S. (2016) 'How can SMEs benefit from big data? Challenges and a path forward' Quality and Reliability Engineering International, 32(6), pp. 2151-2164.

Demchenko, Y., Grosso, P., De Laat, C., and Membrey, P. (2013) 'Addressing big data issues in Scientific Data Infrastructure', in 2013 International Conference on Collaboration Technologies and Systems (CTS), San Diego, CA, USA: IEEE, pp. 48-55.

Eisenhardt, K., Furr, N., and Bingham, C. (2010) 'CROSSROADS-Microfoundations of performance: Balancing efficiency and flexibility in dynamic environments', Organization Science, 21(6), pp. 1263-1273.

Eisenhardt, K., and Martin, J. (2000) 'Dynamic capabilities: what are they?', Strategic Management Journal, 21(10-11), pp. 1105-1121.

Elbashir, M. Z., Collier, P. A., and Davern, M. J. (2008) 'Measuring the effects of business intelligence systems: The relationship between business process and organizational performance', International Journal of Accounting Information Systems, 9(3), pp. 135-153.

Elberse, A. and Ferguson, A. (2013) 'Ferguson's Formula', Harvard Business Review, 91(10), pp. 116-125.

Erevelles, S., Fukawa, N., and Swayne, L. (2016) 'Big Data consumer analytics and the transformation of marketing', Journal of Business Research, 69(2), pp. 897-904.

e-skills UK (2013). 'Big Data Analytics, Adoption and Employment Trends, 2012- 2017'. SAS Available at: https://www.thetechpartnership.com/globalassets/pdfs/research2013/bigdataanalytics report nov2013.pdf (Accessed 17 July 2018). 
George, G., Haas, M. R., and Pentland, A. (2014) 'Big data and management', Academy of Management Journal, 57(2), pp. 321-326.

Ghobadian, A., and Gallear, D. N. (1996) 'Total quality management in SMEs', Omega, 24(1), pp. 83-106.

Grant, R. M. (2005) Contemporary strategy analysis. 5th ed. Malden, MA: Blackwell Pub.

Guarda, T., Santos, M., Pinto, F., Augusto, M., and Silva, C. (2013) 'Business intelligence as a competitive advantage for SMEs', International Journal of Trade, Economics and Finance, 4(4), p. 187-190.

Gupta, M., and George, J. F. (2016) 'Toward the development of a big data analytics capability', Information \& Management, 53(8), pp. 1049-1064.

Helfat, C., and Peteraf, M. (2003) 'The dynamic resource-based view: Capability lifecycles', Strategic Management Journal, 24(10), pp. 997-1010.

Haug, A., and Arlbjørn, J. (2011) 'Barriers to master data quality', Journal of Enterprise Information Management, 24(3), pp. 288-303.

Hoopes, D. G., and Postrel, S. (1999) 'Shared knowledge," glitches," and product development performance', Strategic Management Journal, 20(9), pp. 837-865.

Johnson, B. D. (2012) 'The Secret Life of Data In the Year 2020', The Futurist, 46(4), pp. 20-23.

Kaplan, R. S. and Norton, D. P. (2004) Strategy maps: converting intangible assets into tangible outcomes. Boston: Harvard Business School Press.

Kaplan, R. S. and Norton, D. P. (2001) The strategy-focused organization: how balanced scorecard companies thrive in the new business environment. Boston: Harvard Business School Press.

Keller, P. A. (2011) Statistical process control demystified. New York: McGraw-Hill

Kiron, D., Prentice, P. K., and Ferguson, R. B. (2012). 'Innovating with analytics' MIT Sloan Management Review, 54(1), p. 47-51.

Kiron, D., and Shockley, R. (2011). 'Creating business value with analytics' MIT Sloan Management Review, 53(1), p .57.

Kitchenham, B. (2004). 'Procedures for performing systematic reviews' Available at: http://www.inf.ufsc.br/ aldo.vw/kitchenham.pdf (Accessed 14 November 2018).

Kraaijenbrink, J., Spender, J. C., and Groen, A. J. (2010) 'The resource-based view: a review and assessment of its critiques', Journal of Management, 36(1), pp. 349-372.

Kumar, M., Antony, J., Madu, C. N., Montgomery, D. C., and Park, S. H. (2008). 'Common myths of Six Sigma demystified' International Journal of Quality \& Reliability Management, 25(8), pp. 878-895. 
Lamba, H. S. and Dubey, S. K. (2015) 'Analysis of requirements for Big Data Adoption to maximize IT Business Value - IEEE Conference Publication', 4th International Conference on Reliability, Infocom Technologies and Optimization (ICRITO) (Trends and Future Directions), Noida, Uttar Pradesh, India, 2-4 September. IEEE, pp. 284-290.

LaValle, S., Lesser, E., Shockley, R., Hopkins, M. S., and Kruschwitz, N. (2011) 'Big data, analytics and the path from insights to value', MIT Sloan Management Review, 52(2), p. 2032.

Mahoney, J. T., and Pandian, J. R. (1992) 'The resource-based view within the conversation of strategic management', Strategic Management Journal, 13(5), pp. 363-380.

Manyika, J., Chui, M., Brown, B., Bughin, J., Dobbs, R., Roxburgh, C., and Byers, A. H. (2011). 'Big data: The next frontier for innovation, competition, and productivity', McKinsey Global Institute. Available at:

https://www.mckinsey.com/ /media/McKinsey/Business\%20Functions/McKinsey\%20Digital/ Our\%20Insights/Big\%20data\%20The\%20next\%20frontier\%20for\%20innovation/MGI big da ta exec summary.ashx (Accessed 14 November 2018).

Marr, B. (2016) Big data in practice: how 45 successful companies used big data analytics to deliver extraordinary results. Chichester, West Sussex: Wiley.

McAfee, A., Brynjolfsson, E., and Davenport, T. H. (2012) 'Big data: the management revolution', Harvard business review, 90(10), pp. 60-68.

Mikalef, P., Pappas, I. O., Krogstie, J., and Giannakos, M. (2018) 'Big data analytics capabilities: a systematic literature review and research agenda', Information Systems and e-Business Management, 16(3) pp. 547-578.

Nerur, S., Mahapatra, R., and Mangalaraj, G. (2005) 'Challenges of migrating to agile methodologies', Communications of the ACM, 48(5), pp. 72-78.

Pierce, J. L., Boerner, C. S., and Teece, D. (2002). 'Dynamic capabilities, competence and the behavioral theory of the firm', in Augier, M. (ed.) The Economics of Choice, Change and Organization. Essays in Memory of Richard M. Cyert. Northampton: Edward Elgar, pp.81-95.

Porter, M. E. (1985) Competitive advantage: creating and sustaining superior performance. New York: Free Press.

Priem, R., and Butler, J. (2001) 'Is the resource-based "view" a useful perspective for strategic management research?', Academy of Management Review, 26(1), pp.22-40.

Reeves, M., and Deimler, M. S. (2009) 'Strategies for winning in the current and postrecession environment', Strategy \& Leadership, 37(6), pp.10-17.

Roy, K., and Khokhle, P. W. (2011) 'Integrating resource-based and rational contingency views: understanding the design of dynamic capabilities of organizations', Vikalpa: The Journal for Decision Makers, 36(4), pp.67-75.

Seddon, J. J., and Currie, W. L. (2017) 'A model for unpacking big data analytics in highfrequency trading', Journal of Business Research, 70, pp.300-307. 
Sharda, R., Delen, D., Turban, E., Aronson, J., and Liang, T. P. (2014) Business Intelligence and Analytics: Systems for Decision Support. London: Prentice Hall.

Sun, E. W., Chen, Y.-T., and Yu, M.-T. (2015). 'Generalized optimal wavelet decomposing algorithm for big financial data' International Journal of Production Economics, 165, pp.194214.

Tallon, P. P., Ramirez, R. V., and Short, J. E. (2013). 'The information artifact in IT governance: toward a theory of information governance' Journal of Management Information Systems, 30(3), pp.141-178.

Tan, W., Blake, M. B., Saleh, I., and Dustdar, S. (2013). 'Social-network-sourced big data analytics' IEEE Internet Computing, 17(5), pp. 62-69.

Teece, D. (2018) 'Business models and dynamic capabilities', Long Range Planning, 51(1), pp. $40-49$.

Teece, D. (2012). 'Dynamic capabilities: Routines versus entrepreneurial action'. Journal of Management Studies, 49(8), p. $1395-1401$.

Teece, D. (2000). 'Strategies for Managing Knowledge Assets: the Role of Firm Structure and Industrial Context' Long Range Planning, 33(1), pp. 35-54.

Teece, D., and Linden, G. (2017). Business models, value capture, and the digital enterprise. Journal of Organization Design, 6(1), p. 1-14.

Teece, D., and Pisano, G. (1994). 'The dynamic capabilities of firms: an introduction' Industrial and Corporate Change, 3(3), pp. 537-556.

Treacy, M., and Wiersema, F. (1993). Customer intimacy and other value disciplines. Harvard Business Review, 71(1), pp. 84-93.

Turban, E., Sharda, R., Aronson, J. E., and King, D. (2008). Business intelligence: A managerial approach. Upper Saddle River, NJ: Pearson Prentice Hall.

Vidgen, R., Shaw, S., and Grant, D. B. (2017). Management challenges in creating value from business analytics. European Journal of Operational Research, 261(2), pp. 626-639.

Wernerfelt, B. (1984). A resource-based view of the firm. Strategic Management Journal, 5(2), pp. 171-180.

Winter, S. (2000). The satisficing principle in capability learning. Strategic Management Journal, 21(10), p. 981-996.

Wixom, B., and Watson, H. (2012). “The Bl-based organization' in Herschel, R. (ed.) Organizational Applications of Business Intelligence Management: Emerging Trends, Hershey PA: IGI Global, pp.193-209. 


\title{
Measuring Social and Psychological Outcomes from Activation Labour Market Programmes in Higher Education: A Pilot Study.
}

\author{
Vanessa Long Hogarty \\ Dublin Business School \\ PhD candidate, Trinity College Dublin \\ Dublin, Ireland \\ Dr Conor Mc Guckin \\ Assistant Professor, \\ School of Education, Trinity College Dublin \\ Dublin, Ireland
}

(C) Author(s). This work is licensed under the Creative Commons Attribution-NonCommercialShareAlike 4.0 International License. To view a copy of this license, visit https://creativecommons.org/licenses/by-nc-sa/4.0/ .

\begin{abstract}
Following the 2008 recession, Ireland experienced unemployment rates as high as 15\% (McGuinness, O'Connell and Kelly, 2014). Policy responses have been through the introduction of upskilling and reskilling through activation labour market policies (ALMPs) in the higher education sector (Department of Education and Skills, 2015). The evidence to date regarding the efficacy of such interventions (e.g., Springboard+) has been concerned with blunt measurements of progression rates, labour market entry, and earnings. The present study explored social capital and social well-being among a sample of 101 participants of Springboard+ programmes at one higher education provider in Dublin. The primary objective of the pilot study is to create and test a research method informed by well validated indicators to inform a larger national study.

Keywords: unemployment; upskilling; reskilling; activation labour market policies; Springboard+; higher education; social outcomes; social capital; social policy; measurement
\end{abstract}

\section{Introduction}

Following the 2008 recession, Ireland experienced unemployment rates as high as $15 \%$ (McGuinness, O'Connell, and Kelly, 2014). Policy responses related to the upskilling and reskilling of the workforce were operationalised through the introduction of activation labour market policies (ALMPs) in the higher education sector (Department of Education and Skills: DES, 2015). The evidence to date regarding the efficacy of such interventions (e.g., Springboard+) has been concerned with blunt measurements of progression rates, labour market entry, and earnings. However, as would be generally expected of any intervention with life-long or life-wide skills and 